\title{
DEPÓSITOS DE SULFETOS METÁLICOS NO FUNDO DOS OCEANOS
}

\author{
Sidney L. M. Mello \& Sandra H. A. J. Quental
}

Received August 23, 2000 / Accepted July 11, 2001

\begin{abstract}
Os processos geológicos que atuam na formação da crosta oceânica são eventuais geradores de intensa atividade hidrotermal, a qual é por sua vez capaz de garantir a existência de uma exótica comunidade biológica em profundidades aonde não chega a luz solar e ainda produzir importantes depósitos minerais. Desde a descoberta do primeiro depósito de sulfetos metálicos na Cadeia do Pacífico Leste, hoje são conhecidos cerca de 100 sítios hidrotermais associados a uma variedade de depósitos minerais. Estas ocorrências têm lugar em diferentes ambientes tectônicos, porém não são contínuas globalmente. Apenas algumas regiões possuem as condições ideais para a formação de plumas hidrotermais, sobretudo aquelas que são influenciadas por anomalias térmicas do manto e, portanto, onde as rochas da crosta oceânica são mais aquecidas em profundidade. Estas rochas devem não somente ser quentes como também possuir falhas, fraturas e fissuras a fim de garantir um caminho bastante permeável para a circulação hidrotermal e a formação de fontes hidrotermais. Ao penetrar na crosta oceânica a água do mar mais fria interage com as rochas intensamente aquecidas e transforma-se num fluido hidrotermal de alta temperatura $\left(300^{\circ}-400^{\circ} \mathrm{C}\right) \mathrm{com}$ baixo $\mathrm{pH}$ e Eh. Este fluido retorna para a superfície lixiviando e transportando metais e outros elementos, os quais serão eventualmente precipitados como depósitos de sulfetos maciços na superfície do fundo oceânico ou como depósitos do tipo stockwork em subsuperfície. Em geral, estes depósitos são encontrados em profundidades médias da ordem de $2500 \mathrm{~m}$ e ocorrem em altas concentrações de cobre (calcopirita), zinco (esfalerita), chumbo (galena) e ainda ouro e prata. Estima-se que os depósitos podem atingir proporções entre 1 e 100 milhões de toneladas. Muitas empresas de mineração têm acompanhado com interesse o desenvolvimento das pesquisas sobre os depósitos de sulfetos metálicos no fundo dos oceanos, até mesmo porque estes têm sido interpretados como análogos modernos de ocorrências de sulfetos metálicos no passado geológico, proporcionando assim melhores modelos para a exploração e explotação mineral no continente. Neste trabalho apresentamos uma revisão sobre a ocorrência dos depósitos de sulfetos metálicos marinhos, com ênfase na sua formação, nos métodos de investigação, na localização dos principais depósitos, na sua mineralogia e conteúdo em metais, no seu potencial como recursos minerais e prováveis impactos na sua explotação.
\end{abstract}

Palavras-chave: Atividade Hidrotermal; Recursos Minerais Marinhos; Depósitos de Sulfetos Metálicos.

METALLIC SULFIDE DEPOSITS IN DEEP SEA - The geological processes that lead to the formation of a new oceanic crust may cause intense hydrothermal activity. This activity supports the existence of an exotic fauna in deep ocean and also forms mineral deposits. Since the discovery of the first hydrothermal field on the East Pacific Rise, there has already been found about 100 hydrothermal sites associated with important metallic sulfide deposits. These sites occur along the oceanic spreading centers in different tectonic settings, but are not continuous globally. They are localized at specific sites where hot rocks are connected to faults and fractures, creating a permeable pathway for the hydrothermal circulation. Seawater penetrates into the oceanic crust and is modified to hydrothermal fluid with high temperature (up to $400^{\circ} \mathrm{C}$ ), low $\mathrm{pH}$ and Eh. This fluid interacts with the rocks leaching and transporting metals, which precipitate as massive 
sulfides at the seafloor or as stockwork in the subseafloor. Metallic sulfide deposits can reach considerable size ranging from 1 to 100 million tones with high concentrations of copper, zinc, lead and precious metals such as gold and silver. Some of these deposits have recently attracted the interest of the scientific community and the international mining industry. They are good examples of modern analogues for understanding the genesis of volcanic-hosted massive sulfides on land and show strong potential mining in the near future. Here we provide a review on the deep-sea sulfide deposits, focusing on its formation, methods of exploration, location and characteristics (mineralogy/metal contents) of the main sites, and also the potential mining impacts.

Keywords: Hydrothermal Activity; Marine Minerals Resources; Metallic Sulfide Deposits.

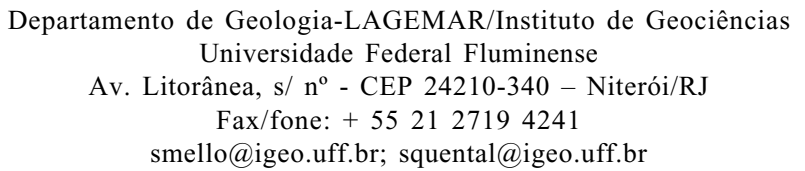

\section{INTRODUÇÃO}

A atividade hidrotermal que ocorre atualmente em centros de expansão oceânicos, seja nas cordilheiras mesoceânicas (midocean ridges) ou nos riftes das bacias de retro-arco em regiões de arcos vulcânicos (back-arc rift basins), transfere grande quantidade de calor e massa do interior da Terra para os oceanos. Sobretudo nestas regiões são encontrados sítios hidrotermais (hydrothermal sites) com notável atividade biológica e importantes depósitos de sulfetos metálicos. Estes depósitos, pioneiramente descobertos na Cadeia do Pacífico Leste (Francheteau et al., 1979), vêm sendo atualmente investigados por programas de pesquisa nacionais e internacionais, visando o melhor entendimento dos processos geológicos que controlam a sua formação e distribuição, bem como a caracterização do ecossistema hidrotermal como um todo, incluindo o seu potencial para exploração mineral e biotecnologia. Como exemplo, destacamse os programas Ridge Inter-Disciplinary Global Experiment (RIDGE- http://ridge.oce.orst.edu/) dos Estados Unidos, British Mid-Ocean Ridge Initiative (BRIDGE- http://www.soc.soton.ac.uk/BRIDGE/) e International Ridge (INTERIDGE- http://triton.ori.utokyo.ac.jp/ intridge/), envolvendo os EUA, Reino Unido, França, Alemanha, Japão, Canadá, Rússia, Austrália, Islândia, Portugal e Noruega. A maioria dos sítios hidrotermais até agora descobertos encontrase nos oceanos Pacífico e Atlântico Norte, enquanto apenas um sítio foi encontrado no Índico e nenhum no Atlântico Sul.
Este trabalho apresenta uma revisão sobre as pesquisas referentes à ocorrência de depósitos de sulfetos metálicos em sítios hidrotermais no fundo dos oceanos e resulta do acompanhamento da literatura pertinente, bem como da nossa participação em pesquisa sobre cordilheiras mesoceânicas e no Programa BRIDGE. Abordamos aqui a formação dos depósitos minerais a partir da circulação hidrotermal e as metodologias correntes para a investigação dos sítios hidrotermais. Apresentamos ainda a localização das ocorrências e suas principais características minerais e, por fim, discutimos as perspectivas econômicas potenciais dos depósitos e prováveis impactos na sua explotação.

\section{CIRCULAÇÃO HIDROTERMAL}

Cerca de $35 \mathrm{~km}^{3}$ de nova crosta oceânica é formada por ano nos centros de expansão. Este processo envolve a geração e resfriamento da litosfera oceânica e contribui com $75 \%$ da perda anual de calor do interior da Terra (Pollack et al., 1993). Um quarto da perda total de calor $\left(1.1 \times 10^{13} \mathrm{~W}\right)$ resulta da circulação hidrotermal (hydrothermal circulation) na crosta oceânica (Stein e Stein, 1994). Esta circulação hidrotermal proporciona trocas químicas entre a água do mar e as rochas oceânicas, agindo como importante regulador da química dos oceanos e do conteúdo de voláteis do interior da Terra. Além disso, é responsável pela formação de depósitos minerais e por viabilizar a vida em ambientes de condições físico-quimícas extremas. 


\section{Fonte dos depósitos minerais}

A Fig. 1 apresenta um modelo esquemático da circulação hidrotermal. A água do mar percola as rochas oceânicas através de falhas, fraturas e fissuras e chega a atingir a base da crosta onde estas estão superaquecidas e, em alguns casos, em estado de fusão parcial (e.g., Cann e Strens, 1982). Deste modo, a água do mar torna-se progressivamente mais quente e reage quimicamente com as rochas alterando a sua composição original. Em função da alta temperatura, a água se expande e tem a sua viscosidade reduzida, facilitando ainda mais o seu fluxo. Se este processo ocorresse em ambiente subaéreo, sob pressão atmosférica (1 bar), a água passaria a vapor a partir dos $100^{\circ} \mathrm{C}$. Entretanto, como as cordilheiras mesoceânicas encontram-se a 2000-4000 metros de profundidade, sob pressões entre 200 e 400 bar, esta chega a atingir temperaturas entre $350^{\circ} \mathrm{C}$ e $400^{\circ} \mathrm{C}$ sem entrar em ebulição. A água quimicamente modificada e fortemente aquecida torna-se bem menos densa do que a água do mar que percola as rochas e, por isto, retorna rapidamente a superfície do fundo oceânico como um fluido hidrotermal. $\mathrm{O}$ movimento do fluido através da rocha é tal que, enquanto o fluxo descendente de percolação é lento e gradual sobre uma ampla área, o fluxo ascendente é muito rápido e concentrado através de dutos naturais, denominados respiradouros termais (thermal vents). Estes respiradouros são em geral bastante reduzidos, podendo ter apenas $10 \mathrm{~cm}$ de diâmetro.

O tempo de residência crustal da água do mar nos sistemas hidrotermais é da ordem de 3 anos (Kadko e Moore, 1988). Dados sobre a interação da água do mar com a rocha indicam que, com o aumento da temperatura, $\mathrm{o} \mathrm{Mg}^{2+}$ e o $\mathrm{SO}_{4}^{2-\text { dissolvidos }}$ na água são precipitados sob a forma de sulfetos minerais e argilas (Alt, 1995). Em altas temperaturas, os metais, sílica e sulfetos são lixiviados da rocha, formando um fluido hidrotermal quente, ácido $(\mathrm{pH}$

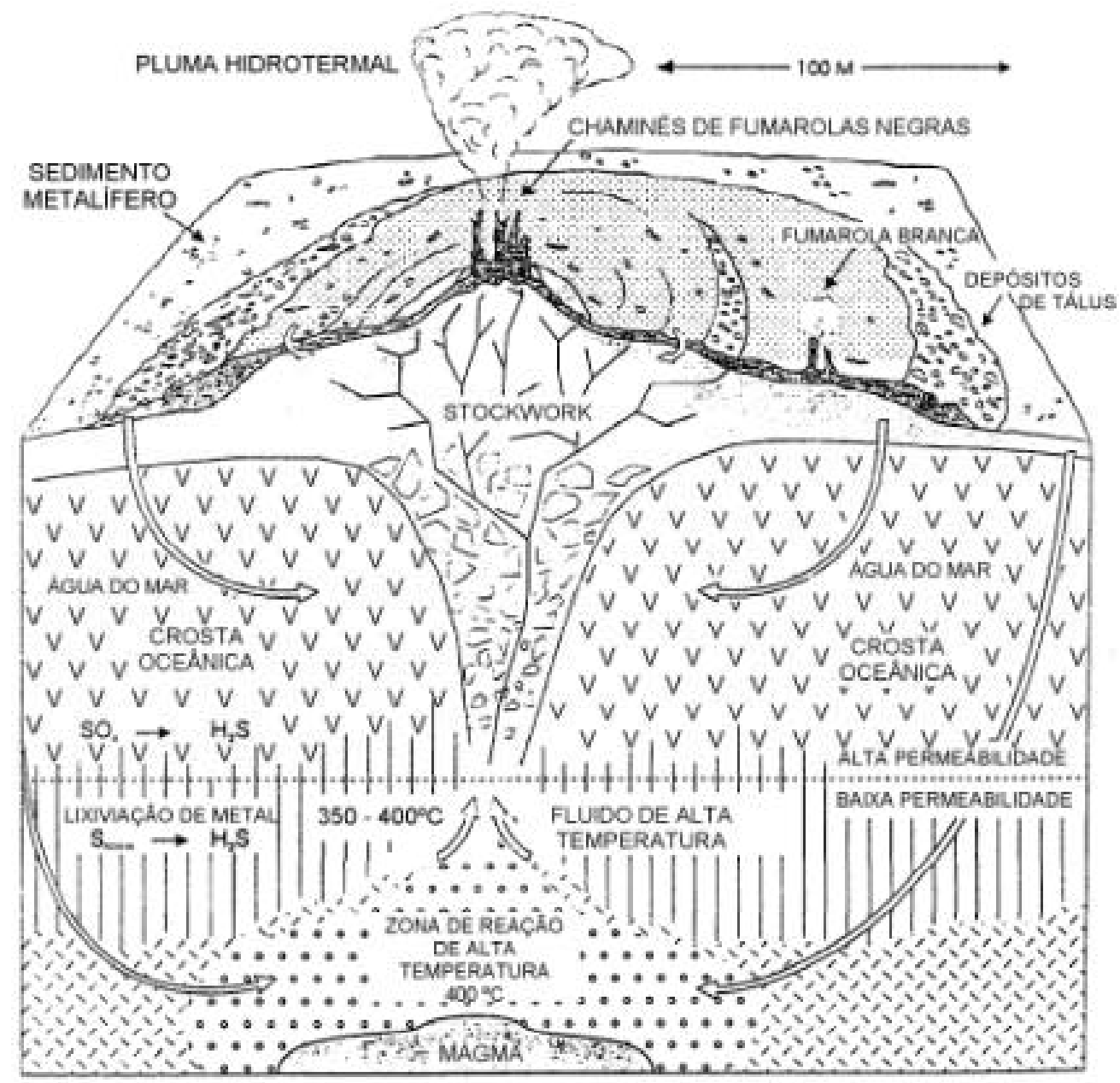

Figura 1 - Diagrama esquemático da circulação hidrotermal e depósitos associados. Modificado de Herzig et al. (2000). 
(a) 2), abundante em sílica, $\mathrm{H}_{2} \mathrm{~S}$ e elementos como $\mathrm{Li}, \mathrm{K}, \mathrm{Rb}, \mathrm{Ca}, \mathrm{Ba}, \mathrm{Fe}, \mathrm{Mn}, \mathrm{Cu}, \mathrm{Zn}, \mathrm{Au}$ e Ag. Este fluido ascende rapidamente e mistura-se com as águas frias, alcalinas e bem oxigenadas do fundo oceânico, causando a precipitação de sulfetos metálicos e óxidos minerais e formando as fumarolas negras (black smokers). A precipitação continuada de sulfetos e óxidos em torno dos respiradouros termais forma edifícios do tipo chaminés (black smoker chimneys) (Fig. 2). Em geral, as chaminés variam de 1 a $30 \mathrm{~m}$ de altura e exalam fluidos hidrotermais em temperaturas de até $400^{\circ} \mathrm{C}$ com velocidade entre $1 \mathrm{e}$ $5 \mathrm{~m} / \mathrm{seg}$. Estes fluidos ainda ascendem por centenas
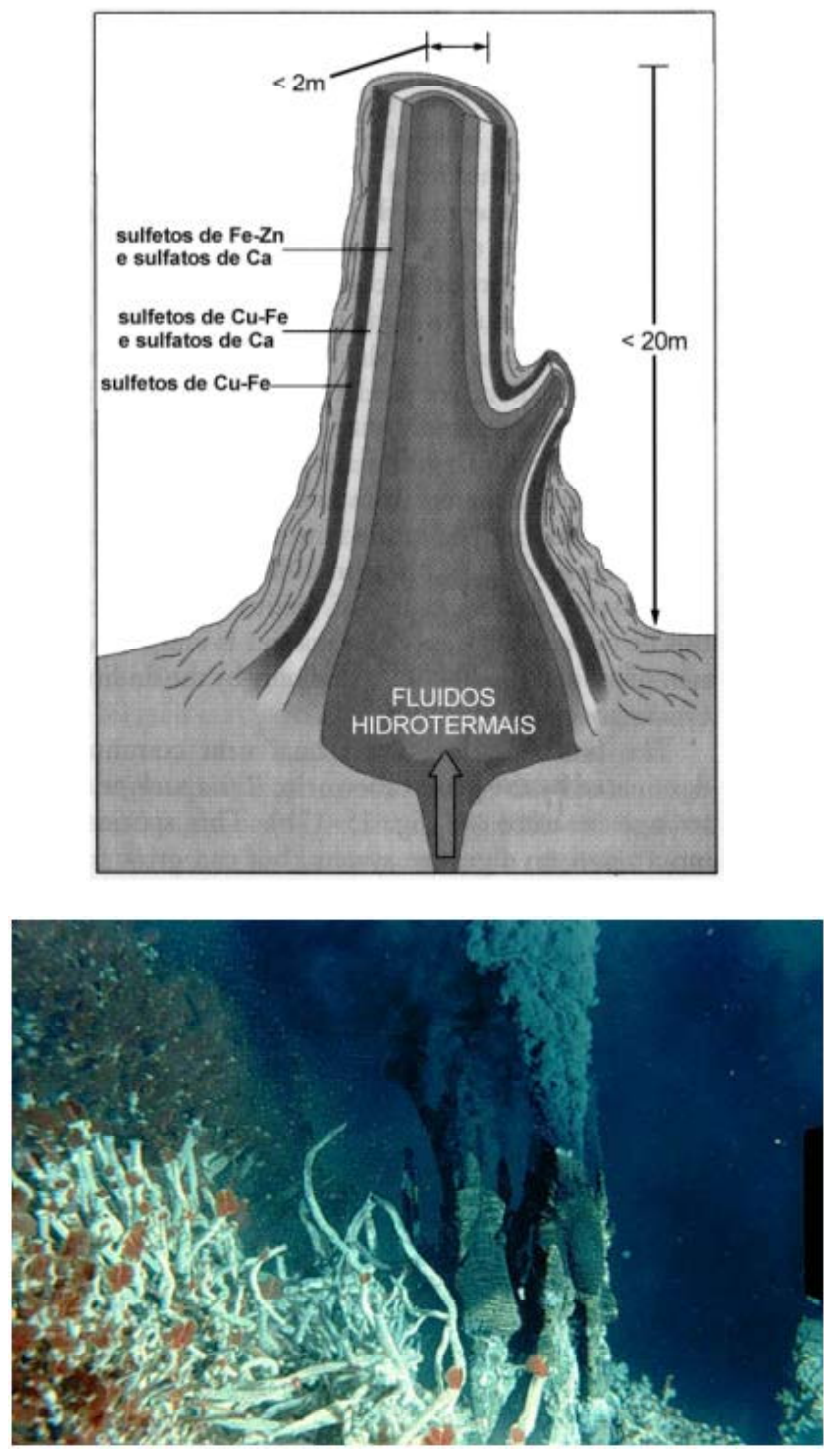

Figura 2 - (a) Estrutura de uma chaminé hidrotermal e (b) Foto de uma chaminé de fumarola negra na Cadeia Juan de Fuca (Dr. Verena Tunnicliffe, http://web.uvic.ca/sciweb/pics/hydrothermalvents.html). de metros acima do fundo oceânico, formando uma grande pluma hidrotermal (hydrothermal plume) que, com o tempo, se mistura com a água do mar.

Um típico campo hidrotermal (hydrothermal field) é formado por várias estruturas do tipo chaminés, dispersas em uma área com aproximadamente 100 $\mathrm{m}$ de raio (Fig. 1). Nestas áreas ocorrem, em superfície, depósitos minerais de sulfetos maciços associados às fumarolas negras, onde a temperatura dos fluidos hidrotermais encontra-se entre $300^{\circ} \mathrm{Ce}$ $400^{\circ} \mathrm{C}$. Estes depósitos são em geral ricos em sulfetos de ferro e cobre, anidrita (sulfato de cálcio) e outros complexos de sulfetos. Depósitos de tálus são
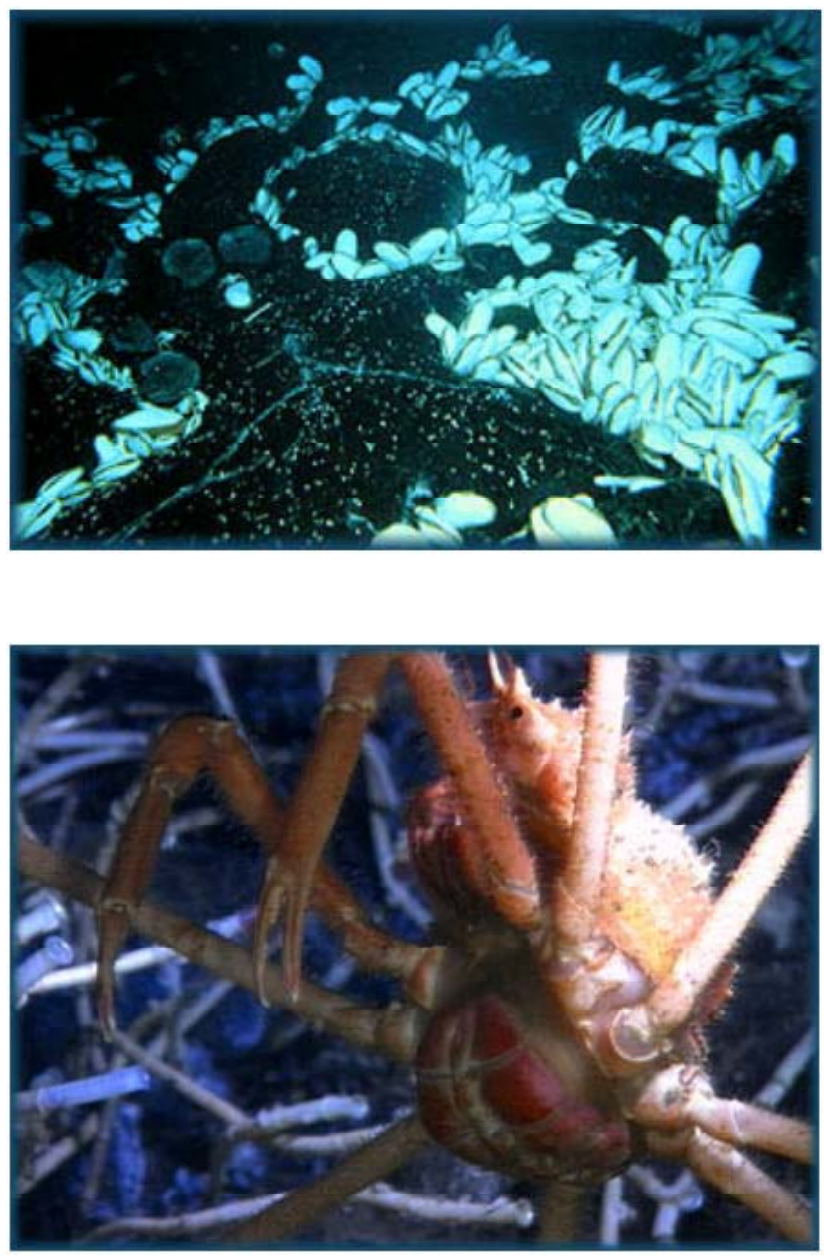

Figura 3 - Exemplos de espécies encontradas em sítios hidrotermais (http://www.amnh.org/nationalcenter/expeditions/ blacksmokers/life_forms.html): (a) Vescomyid clams, fotografados sobre lavas na Cadeia do Pacífico Leste, 950' N (Dr. Dan Fornari, Deep Submergence Operations Group, Woods Hole Oceanographic Institution, EUA); (b) Espécie de caranguejo fotografado no Segmento Endeavor da Cadeia Juan de Fuca (47 $57^{\prime}$ $\mathrm{N}, 129^{\circ} 6^{\prime} \mathrm{W}$ ) por observadores do submersível $A L V I N$. (Dr. J. R. Delaney, Universidade de Washington, EUA). 
observados nos flancos das elevações mineralizadas e mais afastado ocorrem ainda os sedimentos metalíferos. Algumas áreas apresentam respiradouros termais de baixa temperatura que emitem fumarolas brancas (white smokers) a partir do fundo oceânico, formando depósitos mais ricos em sulfetos de zinco. A temperatura dos fluidos hidrotermais emitidos pelos respiradouros de fumarolas brancas (white smoker thermal vents) variam entre $20^{\circ} \mathrm{C}$ e $300^{\circ} \mathrm{C}$. Particularmente, os respiradouros termais de mais baixa temperatura liberam águas quentes reluzentes (hot shimmering water) que são 5 a 10 vezes ainda mais quentes do que água do mar em oceano profundo $\left(2-3^{\circ} \mathrm{C}\right)$. Em subsuperfície, dentro da zona principal de passagem do fluxo hidrotermal (upflow zone), ocorrem os depósitos de sulfetos metálicos do tipo stockwork. Como um todo, o campo hidrotermal mostra um zoneamento concêntrico com os depósitos de sulfetos de alta temperatura no centro e os sulfetos e óxidos de ferro de baixa temperatura distribuídos lateralmente.

\section{Vida nos sítios hidrotermais}

Os campos hidrotermais apresentam também um complexo ecossistema nunca antes imaginável no fundo dos oceanos, o qual exibe uma enorme riqueza biológica num habitat em a luz solar não chega e, portanto, não se processa a fotossíntese (e.g., Van Dover, 2000). A descoberta de diversas novas espécies, entre bactérias, organismos zooplanctônicos, enormes mexilhões e vermes (Fig. 3) durante pesquisas em sítios hidrotermais submarinos surpreendeu a comunidade científica e a levou ao interesse no estudo da fonte de energia desses ecossistemas. De acordo com Sarrazin e Juniper (1999), a biomassa da fauna de respiradouros hidrotermais pode chegar a 500 a 1000 vezes o valor da biomassa na circunvizinhança, atingindo valores similares aos dos ecossistemas marinhos mais produtivos.

A razão da existência deste verdadeiro oásis no fundo dos oceanos a mais de 2500 metros de profundidade está associada à oferta de alimentos. Devido à presença de sulfeto de hidrogênio nos fluidos hidrotermais, associada à abundância de bactérias capazes de oxidá-los, concluiu-se que a produtividade biológica nos sítios hidrotermais deveria provir de quimiossíntese de matéria orgânica por esses microorganismos (e. g., Corliss et al., 1979; McCollom e Shock, 1997). Desta forma, a oxidação química de sulfeto de hidrogênio e outras substâncias redutoras constituiria a energia necessária para a síntese de matéria orgânica.

Os microorganismos quimiossintetizantes estão aparelhados para atuar num ambiente extremamente tóxico à maioria da vida no nosso planeta e formam a base de uma cadeia alimentar que reúne um grande número de exóticos animais. Nos respiradouros hidrotermais, muitos organismos quimiossintetizantes vivem em simbiose com os tecidos de vermes e bivalves gigantes (Nelson e Fisher, 1995). Outros crescem livremente formando biofilmes e filamentos sobre superfícies minerais e animais. Predadores e escavadores locais ou atraídos de águas vizinhas completam a teia alimentar do ecossistema. Nos veios hidrotermais subsuperficiais e nas plumas, a quimiossíntese microbiana também ocorre, mas poucos estudos foram realizados nesses habitats (e.g., Burd e Thomson, 1995).

A biodiversidade e a densidade da fauna dos sítios hidrotermais estão intimamente ligadas à taxa de expansão do fundo marinho (Junniper e Tunnicliffe, 1997; Tunnicliffe et al., 1996). Desta forma, os ecossistemas que habitam os respiradouros da Cadeia do Pacífico Leste (CPL) diferem significativamente daqueles que habitam os respiradouros da Cordilheira Mesoatlântica (CMA). Na CPL, onde a taxa de expansão é rápida (cerca de $100 \mathrm{~mm} / \mathrm{ano}$ ), a biodiversidade é reconhecidamente maior do que na CMA. Lá se encontram os maiores mexilhões e vermes até hoje estudados. Aparentemente na CMA as formas de vida visualmente espetaculares são ausentes.

Em relação à evolução genética e às semelhanças e diferenças entre comunidades de sítios hidrotermais de uma mesma cordilheira mesoceânica, algumas considerações podem ser feitas. Surpreendentemente as mesmas espécies podem ser encontradas habitando respiradouros distantes centenas a milhares de quilômetros entre si. Tal fato induz à teoria de que as larvas são transportadas pelas correntes oceânicas por grandes distâncias ao longo do eixo das cordilheiras. Caso elas encontrem uma 
barreira física entre áreas da mesma cordilheira, as populações evoluirão distintamente, de acordo com mutações naturais ou mesmo extinção local. Caso contrário, as espécies serão semelhantes entre si em toda a extensão da cordilheira (Tunnicliffe et al., 1998). Descontinuidades de profundidade também podem ser barreiras para o transporte de larvas, uma vez que a mistura vertical em águas profundas é muito limitada, fazendo com ocorre praticamente apenas movimentos horizontais (e.g., Craddock et al., 1995 e France et al., 1992).

Próximo aos campos hidrotermais existe tanta energia por metro quadrado como nas áreas ensolaradas das florestas tropicais, por isto a abundância de nutrientes e a proliferação de vida. Várias linhas de evidência sugerem que a vida na Terra tenha surgido há 4 bilhões de anos em ambientes similares ao das fontes hidrotermais hoje encontradas nas cordilheiras mesoceânicas (e.g., Nisbet e Fowler, 1996). Deste modo, as cordilheiras mesoceânicas não só representam o local onde nova crosta oceânica está se sendo formada, mas também um laboratório natural para se investigar a origem da vida em nosso planeta.

\section{PESQUISAS EXPLORATÓRIAS DOS SÍTIOS HIDROTERMAIS}

A mistura dos fluidos hidrotermais quentes com água do mar provoca sobre os respiradouros a formação de uma pluma, que ascende devido à sua flutuabilidade até ocorrer dispersão lateral (Middleton e Thomson, 1986; Little et al., 1987; Speer e Rona, 1989). Os fluidos hidrotermais são enriquecidos até $10^{7}$ vezes principalmente em ferro, manganês, metano e hélio, em relação a águas profundas típicas. Deste modo, as anomalias químicas associadas a plumas hidrotermais podem ser detectadas a distâncias significativas dos sítios hidrotermais, sendo utilizadas para rastreá-las e, conseqüentemente, localizar a fonte de emanação dos fluidos.

O traçador ideal de descargas hidrotermais seria o $\mathrm{He}^{-3}$, uma vez que sua inércia geoquímica permite que seu sinal na coluna d'água persista a longas distâncias da fonte (e.g., Baker et al., 1995). No entanto, na prática as medições de $\mathrm{He}^{-3}$ dissolvido exigem uma logística de amostragem sistemática seguida de uma lenta e trabalhosa técnica de análise em laboratórios especializados. Os traçadores mais utilizados são, portanto, o Mn dissolvido e o $\mathrm{CH}_{4}$, cujas análises podem ser feitas a bordo do navio de pesquisa, algumas horas após as amostras de água serem coletadas.

Além dos traçadores químicos, sensores óticos para captar a atenuação de luz e seu espalhamento têm sido amplamente empregados no mapeamento de plumas hidrotermais. Os traçadores óticos são nãoconservativos e dependem do balanço entre produção de partículas por precipitação (também crescimento biológico) e perda de partículas por deposição, dissolução e ingestão. Estes traçadores são geralmente mais sensíveis e simples de interpretar do que os traçadores hidrográficos.

Atualmente, a metodologia mais popular para detecção de novos sítios hidrotermais é a integração de métodos geofísicos e geoquímicos. Primeiramente, é necessário um levantamento batimétrico multifeixe (multibeam) da área. Em seguida, emprega-se o sonar de varredura lateral (sidescan sonar) para um melhor detalhamento da área. Neste sistema são instalados sensores óticos que transmitem informações em tempo real à superfície. De maneira geral os levantamentos até agora realizados na cordilheira mesoceânica têm mostrado que um mês de operação de navio é suficiente para cobrir $100 \%$ de $200 \mathrm{~km}$ de crista.

Em geral, o primeiro levantamento (geofísico) sobre uma região de crista de cordilheira é importante para se localizar o campo de emanações hidrotermais, reduzindo a área de pesquisa de 200 para cerca de 2-5 km, onde os respiradouros termais poderão ser mapeados. Para a localização dos respiradouros, utiliza-se a combinação de um sistema convencional de CTD (e.g., Klinkhammer et al., 1986) interfaceado com um transmissômetro e/ou um nefelômetro. Atualmente existem alguns diferentes equipamentos para amostragem. O mais simples deles consiste na aplicação de amostradores verticais fixos espaçados ao longo do eixo da cordilheira. Uma segunda técnica, bastante utilizada, consiste no uso de tow-yos; os amostradores são suspensos e baixados continuamente dentro da pluma enquanto são lentamente rebocados. $\mathrm{Na}$ última e mais moderna 
técnica, desenvolvida primeiramente pelo IFREMER, o amostrador de água é rebocado continuamente (Dynamic Hydrocast; Bougault et al., 1990). O sistema possui quatro grupos de rosetas de água, cada um com um sensor CTD e uma unidade de registro, presos a um cabo e rebocados a diferentes e conhecidas profundidades. Cada conjunto de rosetas possui dez garrafas que se enchem progressiva e seqüencialmente. Adaptações deste amostrador já foram implementadas por outras instituições, resultando em equipamentos cada vez mais sofisticados e eficazes, como o SCANNER (Submersible Chemical Analyzer; Johnson et al., 1986), o SUAVE (uumersible System Used to Assess Vented Emissions; da NOAA) e o ZAPS (Zero Angle Photon Spectrophotometer; Klinkhammer et al., 1994).

Uma vez localizado o sítio hidrotermal, devem ser iniciadas as pesquisas sobre seu potencial de recursos minerais. Normalmente investiga-se a área através de submersíveis ou operados remotamente para visualização e amostragem dos sulfetos metálicos.

\section{LOCALIZAÇÃO DAS PRINCIPAIS OCORRÊNCIAS}

Em apenas duas décadas, desde a descoberta do primeiro depósito hidrotermal no Oceano Pacífico, já foram documentadas cerca de 100 ocorrências importantes em diferentes ambientes tectônicos (Rona, 1988; Rona e Scott, 1993; Hannington et al., 1994). Os depósitos de sulfetos metálicos têm sido principalmente encontrados em ambientes tectônicos onde são evidenciados processos hidrotermais associados a vulcanismo submarino (Fig. 4). Estes ocorrem majoritariamente nas cordilheiras mesoceânicas, mas também, em regiões de colisão de placas oceânicas, associados aos centros de expansão nas bacias de retro-arco e ainda em montes submarinos junto às cordilheiras mesoceânicas. Até o presente não foram documentadas ocorrências em montes submarinos do tipo intraplaca relacionados a pontos quentes (hotspots).

Os depósitos hidrotermais têm sido mais mapeados sobre as cristas da Cadeia do Pacífico Leste do que em qualquer outra região do globo, principalmente na região das cordilheiras ExplorerJuan de Fuca-Gorda, no Golfo da Califórnia e ainda na Cadeia do Pacífico Leste entre $9^{\circ} \mathrm{Ne} 13^{\circ} \mathrm{N}$ e entre $13^{\circ} \mathrm{S}$ e $22^{\circ} \mathrm{S}$ (Baker et al., 1995). A maioria dos depósitos estudados ocorre sob a forma de sulfetos maciçosque afloram na superfície do fundo oceânico, todavia os depósitos na Bacia Guaymas no Golfo da Califórnia e Middle Valley na Cordilheira de Juan Fuca são notáveis exemplos de acumulação de sulfetos em regiões cobertas por sedimentos (Mottl et al., 1991; Zierenberg et al., 1996). As taxas de expansão oceânica nestes diferentes sítios variam de uma média de $60 \mathrm{~mm} /$ ano no Pacífico NE e no Golfo da Califórnia para taxas intermediárias de 110-120 mm/ ano próximo a $10^{\circ} \mathrm{N}$ e super-rápidas de mais de 150 $\mathrm{mm}$ /ano próximo a $20^{\circ} \mathrm{S}$ (e.g., De Mets et al. 1990).

Até 1984 acreditava-se que a atividade hidrotermal restringia-se aos centros de expansão médios a super-rápidos do Oceano Pacífico e que em centros lentos ( $<50 \mathrm{~mm} / \mathrm{ano}$ ), como ao longo da CMA, o fluxo de calor seria insuficiente para suportar atividades hidrotermais de alta temperatura capazes de produzir grandes campos de fumaloras negras (black smoker vent fields). Entretanto, análises de Klinkhammer et al. (1985) revelaram anomalias de Mn dissolvido na água do mar ao longo da CMA entre $11^{\circ} \mathrm{N}$ e $26^{\circ} \mathrm{N}$, sugerindo com isso a existência de atividade hidrotermal em pelo menos cinco sítios no Oceano Atlântico. A primeira descoberta no oceano Atlântico foi o campo hidrotermal TAG (Rona et al., 1986) e hoje são conhecidas outras importantes ocorrências como Logatchev, Snakepit, Broken Spur, Lucky Strike e Menz Gwen (Krasnov et al., 1995). Ao contrário do que se poderia imaginar, não existem evidências de vários sítios hidrotermais na Cadeia Reykjanes, ao sul do ponto quente da Islândia. Pesquisa sistemática entre $57^{\circ} 45^{\prime} \mathrm{N}$ e $63^{\circ} 09^{\prime} \mathrm{N}$ realizada por German et al. (1994) revelou uma única ocorrência de atividade hidrotermal em Steinahóll $\left(63^{\circ} 06^{\prime} \mathrm{N}\right)$. O sítio situa-se em 250-300 m de lâmina d'água e é notável pela formação de plumas hidrotermais ricas em bolhas, conforme imageadas a partir de um ecobatímetro de alta freqüência (38 kHz).O limite oeste do Oceano Pacífico contém diversas bacias marginais e calhas estruturais associadas aos sistemas fossa-arco de ilhas (Taylor e 
Karner, 1983). Muitas dessas bacias e calhas contêm centros de expansão oceânicos ativos na região atrás dos arcos vulcânicos e, deste modo, desenvolvem atividades hidrotermais. Os exemplos mais notáveis estão localizados nas seguintes regiões: Bacia do Norte de Fiji (Auzende et al. 1994), Bacia Lau (Fouquet et al., 1991), Bacia Woodlark no Mar de Solomon (Binns et al. 1993), Bacia Manus no Mar de Bismark (Gamo et al., 1993), Calha de Harve (Harve Trough), Calha de Mariana (Mariana Trough) (Horibe e Craig, 1987) e Calha de Okinawa (Okinawa Trough) (Ishibashi et al. 1988).

\section{CARACTERÍSTICAS DOS DEPÓSITOS}

Análise de amostras de 50 depósitos de sulfetos metálicos indicam uma modesta quantidade de metal, algo em torno de centenas de toneladas (Herzig et al., 2000). Todavia, com base nos dados existentes e na falta de informação tridimensional sobre os depósitos, torna-se ainda prematuro qualquer diagnóstico a respeito do significado econômico dos sulfetos maciços no fundo oceânico. Um grande número de amostras tem sido recuperado no fundo dos oceanos a partir de operações com submersíveis. Com isto a estimativa dos depósitos, em geral, reflete apenas os dados das amostras coletadas ao redor das fumarolas, sobretudo nas chaminés. Contudo é muito improvável que estas amostras sejam representativas da composição total dos depósitos (p.ex., 11 amostras analisadas ao sul da Cordilheira de Juan de Fuca têm uma média de conteúdo em toneladas úmidas (tu) de $\mathrm{Zn}$ maior do que $34 \%$ ) e ainda pouco é conhecido sobre o interior das colinas (mounds) formadas pelos depósitos.

Amostragens sistemáticas de assembléias minerais em sítios hidrotermais ativos de alta e baixa temperatura (e.g., campo hidrotermal TAG, Cordilheira Explorer e Rifte de Galápagos) são mais representativas do espectro de sulfetos metálicos que compreendem os grandes depósitos. De fato, apenas em alguns sítios foram realizadas amostragens visando estimativas realísticas sobre concentração de metais (e.g., Middle Valley, Cordilheira Explorer e Rifte de Galápagos), enquanto análise quantitativa do conteúdo destes foi somente realizada na Depressão Atlantis II
(Atlantis II Deep) no Mar Vermelho. Informações adequadas sobre a concentração e continuidade dos depósitos em profundidade foram obtidas através de perfurações do Programa de Perfuração do Oceano (Ocean Drilling Program - ODP) no campo TAG (Herzig et al., 1998) e no campo Middle Valley (Mottl et al., 1991; Zierenberg et al., 1996).

A característica dos depósitos de sulfetos nos vários ambientes tectônicos, incluindo sua mineralogia e conteúdo em metais, é conseqüência da natureza das rochas das quais os metais são lixiviados. As rochas nos diferentes ambientes tectônicos variam de típicos basaltos das cordilheiras mesoceânicas (midocean ridge basalts - MORBs) cobertos ou não por sedimentos, até lavas bimodais (andesitos-basaltos) em ambientes intraoceânicos em bacias de retro-arco e vulcânicas félsicas (dacitos e riolitos) que são típicos de riftes intracontinentais jovens. Estas variações composicionais refletem diferenças nos fluidos hidrotermais e, conseqüentemente, nos depósitos.

\section{Mineralogia}

A mineralogia dos depósitos de sulfetos metálicos no fundo dos oceanos (Tab. 1) vem sendo caracterizada a partir da análise das amostras nos diferentes ambientes (e.g., Kastner et al., 1987; Haymon e Kastner, 1981; Goldfarb et al., 1983; Hannington et al., 1991; Fouquet et al., 1993; Fouquet et al., 1988). A paragênese mineral dos depósitos de sulfetos em ambientes controlados por intensa atividade vulcânica inclui assembléias minerais formadas em temperaturas entre $300^{\circ}-400^{\circ} \mathrm{C}$. Os depósitos de sulfetos, acumulados em colinas e nas chaminés, são formados em sua porção mais interna por pirita, calcopirita, pirrotita, e localmente bornita. A porção externa consiste de precipitados de baixa temperatura tais como esfalerita e pirita, os quais ocorrem também como principais sulfetos minerais associados às chaminés de fumarolas brancas. A anidrita é um mineral importante nas assembléias minerais de alta temperatura, mas é posteriormente substituída por sulfetos, sílicas amorfas ou barita em baixas temperaturas.

A mineralização de sulfetos em regiões de arcos de ilhas tem a mesma característica dos precipitados 


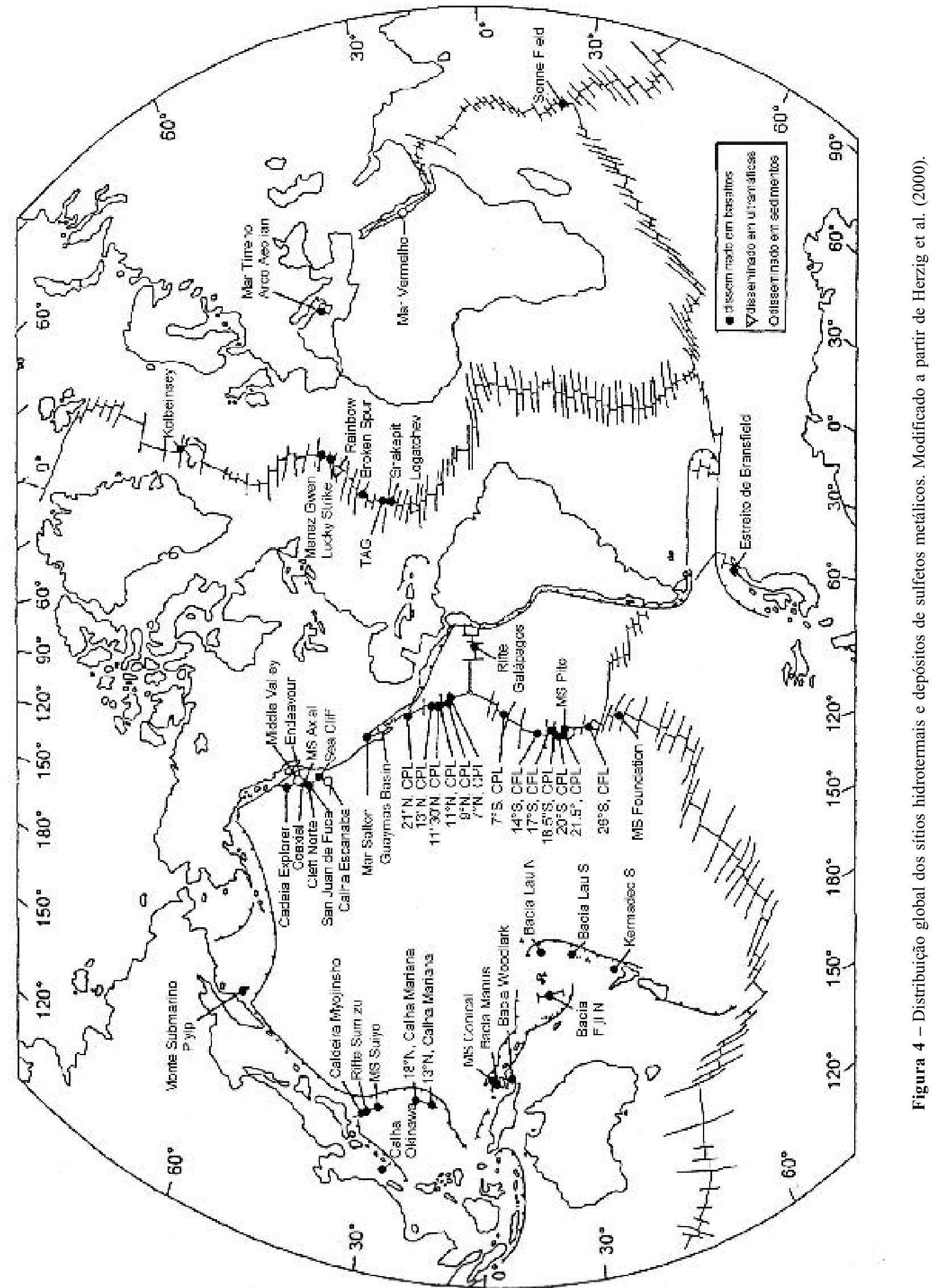


hidrotermais das cordilheiras mesoceânicas. Comumente, ocorrem pirita e esfalerita como sulfetos dominantes. Calcopirita é comum em assembléias de alta temperatura, mas a pirrotita ocorre raramente. Os principais não sulfetos são barita e sílica amorfa. Muitos depósitos nestas regiões apresentam traços de galena, tetraedrita, realgar e ouropigmento. Herzig et al. (1990 e 1993) documentaram a primeira ocorrência de ouro em amostras de sulfetos em chaminés de fumarolas brancas (baixa temperatura $<$ $300^{\circ} \mathrm{C}$ ) na Bacia Lau. O ouro ocorre como grãos grosseiros (18 microns) em inclusões de esfalerita pobre em Fe.

\section{Conteúdo em metais}

A Tab. 2 compara os resultados de análises químicas de depósitos de sulfetos revelando uma tendência na sua composição nos diferentes ambientes tectônicos. As regiões que apresentam sulfetos maciços cobertos por sedimentos (e.g., Calha Escanaba e Bacia Guaymas) aparentemente são maiores do que os depósitos formados sobre rocha vulcânica isenta de cobertura sedimentar. Entretanto, mostram proporções variáveis de metais em menores concentrações. Os sulfetos maciços destes depósitos têm em média 4,7 \% tu de Zn, 1,3\% tu de Cu e 1,1 $\%$ tu de $\mathrm{Pb}$, refletindo a influência de espessa seqüência sedimentar sobre os fluidos hidrotermais que chegam à superfície e tendem a dispersar os metais na interface sedimento-água. A calcita, anidrita, barita e sílica são os maiores componentes dos precipitados hidrotermais nos depósitos cobertos por sedimentos. Nos depósitossobre crosta oceânica, livre de sedimentos, os sulfetos são precipitados principalmente em torno dos respiradouros e por esta razão os depósitos são menores, mas com altas concentrações de metais. Os maiores depósitos para os quais existe uma suíte representativa de amostras (e.g., Cordilheira Explorer, Cadeia do Pacífico Leste, Cordilheira Endeavour, Monte Submarino Axial, Segmento Cleft, Rifte de Galápagos, TAG e Snakepit) apresentam uma estreita faixa de concentração de metal e uma média de $8,5 \%$ tu de $\mathrm{Zn}$ e $4,8 \%$ tu de $\mathrm{Cu}$, mas somente baixas concentrações de $\mathrm{Pb}(0,1$ $\%$ tu). Anidrita, barita e sílica são importantes constituintes de algumas chaminés, mas em média compõem menos do que $20 \%$ das amostras analisadas. A composição dos depósitos nas cordilheiras mesoceânicas, sem qualquer cobertura sedimentar, é de maneira geral semelhante e reflete processos de alta temperatura. Portanto, a variação na concentração dos metais pode representar uma tendência na amostragem ou diferenças nas condições de formação.

Os sulfetos maciços formados em ambientes intraoceânicos sobre crosta de composição basáltica a andesítica (e.g., Calha Mariana, Bacia Manus, Bacia do Norte de Fiji, Bacia Lau) são caracterizados por uma média elevada de $\mathrm{Zn}(16,5 \% \mathrm{tu}), \mathrm{Pb}(0,4 \% \mathrm{tu})$, $\mathrm{Ba}(12,6 \%$ tu) e baixo conteúdo de Fe (1\% tu). Por outro lado, os sulfetos polimetálicos na Calha Okinanawa, onde riolitos e dacitos são produtos do rifteamento atrás do arco, em crosta continental, apresentam ainda menos $\mathrm{Fe}(6.2 \%$ tu), porém são enriquecidos em $\mathrm{Zn}(20,2 \%$ tu $)$ e $\mathrm{Pb}(11,8 \%$ tu $)$ e têm alta concentração de $\mathrm{Ag}$ (2.300 ppm, máximo $1,1 \%$ tu), As ( $1,8 \%$ tu e Sb $(0,7 \%$ tu). O alto Sb e As respondem pela presença da tetraerita, estibnita e sulfetos de As (realgar e ouropigmento).

O conteúdo de ouro é localmente alto em um número de amostras de depósitos na CMO (Hannington e Scott, 1989) e particularmente em amostras de centros de expansão junto aos arcos vulcânicos (Herzig et al., 1993). A média do conteúdo de ouro para depósitos nas CMO varia de menos de 0,2 até 2,6 ppm de Au. Em depósitos de alta temperatura $\left(350^{\circ} \mathrm{C}\right)$, isentos de sedimentos e dominados por processos vulcânicos, os compostos de sulfetos de $\mathrm{Cu}$-Fe contêm menos de 0,2 ppm de $\mathrm{Au}$. As maiores concentrações de ouro ocorrem à baixa temperatura $\left(<300^{\circ} \mathrm{C}\right)$ juntamente com sulfetos de Zn, barita e sílica amorfa (e.g., Axial Seamount 6,7 ppm de Au e Snakpit 10,7 ppm de Au). O ouro parece ser mais abundante em sulfetos associados com riftes imaturos em crostas de arcos continentais ou arcos de ilhas. Estes ambientes são dominados por vulcânicas calcoalcalinas, incluindo andesitos, dacitos e riolitos (e.g., Calha Okinawa, Bacia Lau, Bacia Manus) (Binns et al., 1993). O mais rico depósito de ouro foi encontrado em Conical Seamount em águas territoriais da Papua Nova Guiné, próximo à Ilha Lihir. 


\begin{tabular}{|c|c|c|}
\hline Sulfetos de $\mathrm{Fe}$ & pirita, marcassita e pirrotita & \\
\hline Sulfetos de Mn & esfalerita e wurtzita & \\
\hline Sulfetos de Cu & calcopirita e isocubanita & \\
\hline Silicatos & sílica am orfa & \\
\hline Sulfatos & anidrita e barita & \\
\hline Sulfetos de $\mathrm{Pb}$ & galena & \\
\hline Sulfetos de As & our opigmento e realgar & pouco freqüentes nas cordilheiras \\
\hline Sulfetos de CuAs-Sb & tennantita e tetraedrita & thesoceânicas \\
\hline Metais nativos & ouro & \\
\hline
\end{tabular}

Modificada a partir de Herzig et al. (2000).

Tabela 1 - Composição mineralógica dos depósitos de sulfetos polimetálicos em regiões de retro-arco e em cordilheiras mesoceânicas.

O máximo de ouro no topo do monte submarino $(2,8$ $\mathrm{km}$ de diâmetro em $1600 \mathrm{~m}$ de profundidade) chega a 230 ppm com uma média de 26 ppm para as 40 amostras analisadas.

\section{Dimensão dos depósitos}

Os maiores depósitos em área são aqueles encontrados em sítios hidrotermais ativos em cordilheiras mesoceânicas cobertas por sedimentos. Perfurações do ODP em áreas cobertas por sedimentos em Middle Valley ao norte de Juan de Fuca Ridge indicam depósitos da ordem de 8-9 milhões de toneladas (Zierenberg et al., 1998). Foram encontrados cerca de $200 \mathrm{~m}$ de espessura de sulfetos maciços e de stockwork. A zona de stockwork sobrepõe-se a um horizonte rico em cobre (deep cooper zone) com até $17 \%$ tu. O campo hidrotermal TAG, localizado a $3600 \mathrm{~m}$ de profundidade na CMA em $26^{\circ} \mathrm{N}$, foi perfurado pelo ODP até a profundidade de $125 \mathrm{~m}$ (Herzig et al., 1998), o que levou a uma estimativa da ordem de 3,9 milhões de toneladas de minério, incluindo os sulfetos maciços na superfície e subsuperfície na zona de stockwork (Hannington et al., 1998). A comparação dos depósitos de sulfetos modernos no fundo oceânico com os antigos no continente como Kidd Creek no Canadá (135 milhões de toneladas) e Neves Corvo em Portugal (262 milhões de toneladas) mostra que nenhum grande depósito ainda foi encontrado no oceano.

O maior depósito de sulfetos metálicos no fundo do mar ainda é o da Depressão Atlantis II (Atlantis II
Deep) no Mar Vermelho (Degens e Ross, 1969), o qual foi descoberto cerca de 10 anos antes da primeira fumarola negra no Pacífico Leste. A mineralização na Depressão Atlantis II consiste principalmente de lamas metalíferas, ao invés de sulfetos maciços. Isto é conseqüência da alta salinidade que os fluidos hidrotermais adquirem quando circulam através dos evaporitos Miocênicos do Rifte do Mar Vermelho. Uma avaliação detalhada dos $40 \mathrm{~km}^{2}$ de depósito indica 90 milhões de toneladas do minério seco com $2,0 \%$ tu de $\mathrm{Zn}, 0,5 \%$ tu de $\mathrm{Cu}, 39 \mathrm{ppm} \mathrm{Ag}$ e 0,5 ppm $\mathrm{Au}$, o que resulta em um conteúdo total de metal precioso de 4000 toneladas de $\mathrm{Ag}$ e 50 toneladas de $\mathrm{Au}$ (Nawab, 1984).

A estimativa de depósitos entre 1 e 100 milhões de toneladas de sulfetos maciços parece uma expectativa provável à luz dos depósitos similares no continente. Contudo, a maioria das ocorrências referese a menos do que poucos milhares de toneladas, consistindo principalmente de depósitos em respiradouros termais e colinas mineralizadas. A espessura dos depósitos é difícil de determinar. Típicas fumarolas negras podem facilmente produzir cerca de 250 toneladas de sulfetos maciços por ano. Assim, os campos hidrotermais com poucas fumarolas negras podem responder por pequenos depósitos, dependendo da duração da sua atividade.

Dos cerca de 100 sítios hidrotermais conhecidos atualmente em fundo oceânico moderno, somente 10 depósitos têm tamanho e grau necessários para futura mineração, embora a informação sobre a espessura deles ainda não seja conhecida (Tab. 3). Todos estes 


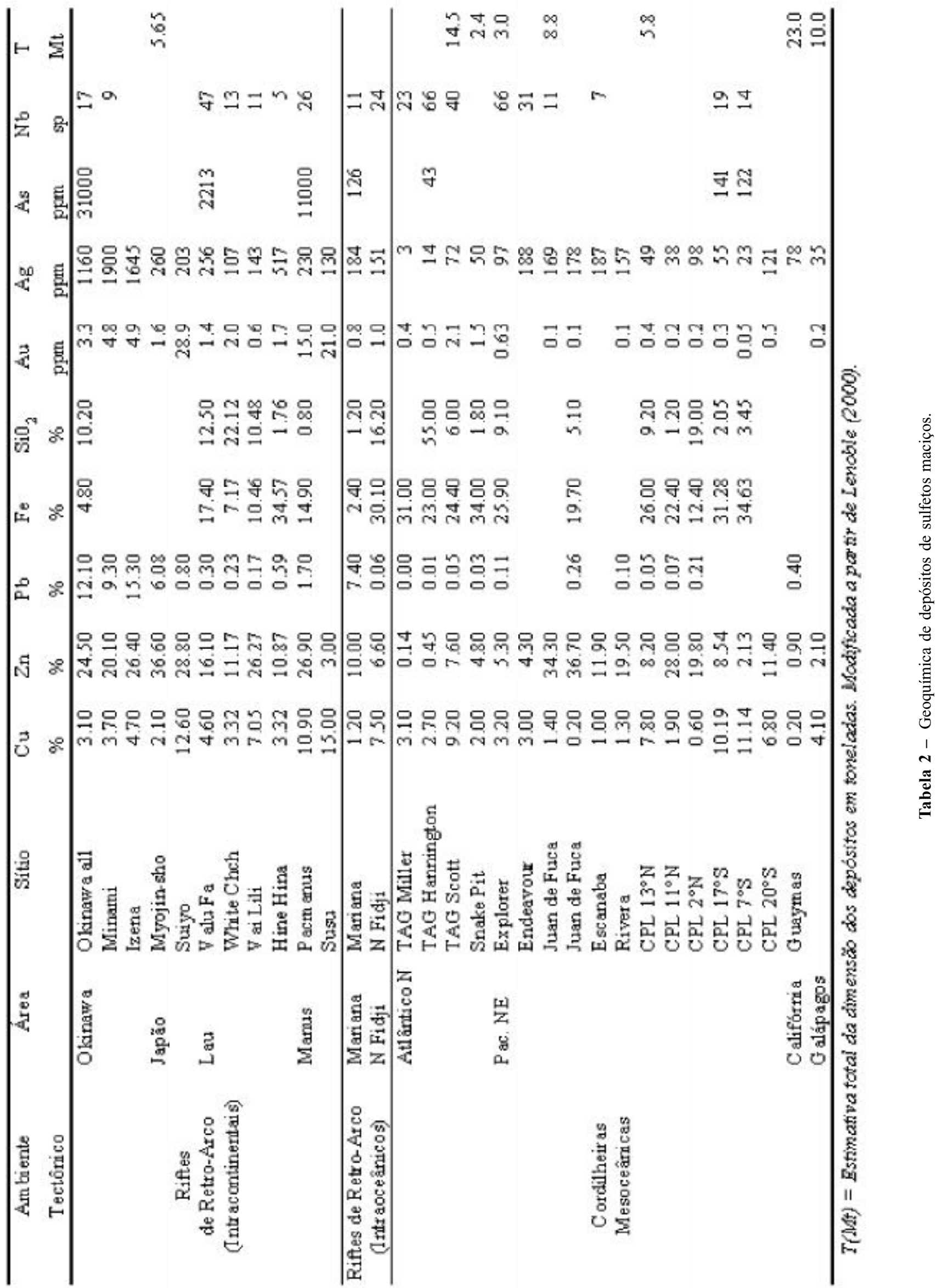


sítios, exceto dois (CPL $13^{\circ} \mathrm{N}$ e TAG), estão localizados dentro das Zonas Econômicas Exclusivas (ZEEs) dos estados costeiros da Arábia Saudita, Sudão, Canadá, Equador, Papua Nova Guiné, Tonga, Japão e Fiji. Particularmente, a Depressão Atlantis II foi o único depósito até o presente avaliado economicamente com base nos padrões aplicados à explotação de minério em terra (Amann, 1985 e 1989). Todavia o futuro da mineração no fundo dos oceanos parece promissor, especialmente considerando a evidência de alta concentração de ouro e outros metais em regiões próximas ao continente, seja dentro da ZEE (200 milhas náuticas) ou do mar territorial (12 milhas náuticas) de alguns Estados costeiros, em profundidade de lâmina d'água da ordem de $2000 \mathrm{~m}$. Sob estas condições, sulfetos maciços podem ser economicamente atrativos, pois inclusive os sistemas de mineração são portáteis e podem mover-se de um sítio para o outro. $\mathrm{O}$ investimento neste sistema e navios não é atrelado a uma localização como em sistemas de mineração continentais, onde o desenvolvimento de infra-estrutura em áreas remotas pode representar um investimento inicial de 350-500 milhões de dólares.

Em dezembro de 1997, o governo da Papua Nova Guiné forneceu a uma empresa de mineração australiana licença de exploração dos seus depósitos de sulfetos metálicos na Bacia Manus (sítios Vienna Woods e Pacmanus).

\section{PROVÁVEIS IMPACTOS AMBIENTAIS DA MINERAÇÃO}

Nas próximas décadas a atividade de extração mineral nos sítios hidrotermais submarinos deverá se restringir a áreas limitadas onde o potencial para explotação comercial é conhecido. No entanto, para que se preservem as comunidades que habitam os sítios hidrotermais, algumas estratégias e regras para a mineração dos depósitos de sulfetos polimetálicos devem ser elaboradas e posteriormente respeitadas pelas empresas mineradoras que se encarregarem desta atividade.

As perturbações causadas pela mineração deverão afetar direta ou indiretamente os organismos nos sítios hidrotermais. Alguns destes seriam imediatamente mortos pelos equipamentos de mineração, enquanto outros seriam submetidos aos efeitos da remoção do substrato duro e da suspensão e posterior precipitação de uma pluma de partículas. Essas partículas entupiriam os dutos de circulação hidrotermal, comprometendo assim a vida dos organismos que dependem do suprimento de fluidos hidrotermais. Pesquisar a capacidade de recolonização das comunidades hidrotermais após eventos extremos torna-se imprescindível para avaliar o provável impacto da mineração nestes ambientes.

Desde o início da década de 90 vêm sendo realizadas pesquisas envolvendo observações dos respiradouros após erupções vulcânicas submarinas (e. g., Tunnicliffe et al., 1997; Haymon et al., 1993) com o objetivo de averiguar a capacidade de recolonização das comunidades que ali vivem. Desde que as emanações de fluidos hidrotermais, as quais garantem a quimiossíntese microbiana, persistam após o evento, observou-se que as comunidades desempenham rapidamente o papel de recolonizar o ambiente. Segundo Juniper (2000), após alguns anos são restabelecidas a biomassa e a densidade de organismos. Sabe-se, no entanto, que o restabelecimento da comunidade depende de uma ou mais "populações-mãe", as quais são particularmente afetadas pela mineração. Juniper e Tunnicliffe (1997) e Juniper et al. (1992) apresentam algumas evidências de que a biodiversidade em uma determinada região é maior em sítios hidrotermais extensos e mais antigos, os quais são aparentemente os melhores locais para acumulação de grandes depósitos de sulfetos e, portanto, serão os alvos primários da mineração. Acredita-se que as populações-mãe com alguma idade são essenciais à manutenção da biodiversidade numa região. Portanto, sua destruição pode ameaçar a recolonização local. No caso de espécies localizadas que não estejam próximo a uma população-mãe, devem ser estabelecidas áreas de proteção para impedir que elas sejam erradicadas.

Nos depósitos hidrotermais inativos, aparentemente a mineração de sulfetos polimetálicos trará menos impactos ambientais. Neles tem sido observada colonização por espécies comuns de oceano profundo, provavelmente atraídas ao local pela disponibilidade de nutrientes. Todavia, como essas 


\begin{tabular}{|c|c|c|c|c|}
\hline Depósito & Area do Oceano & Profundidade & Jurisdição & Pais \\
\hline Depressão Atlantis II & Mar Vermelho & $2.000-2.200 \mathrm{~m}$ & ZEE & Arábia Saudita e Sudão \\
\hline Middle $\mathrm{V}$ alley & Pacifico lv ordeste & $2.400-2.500 \mathrm{~m}$ & ZEE & Canada \\
\hline Cordilheir a Ex plorer & Pacífico Nordeste & $1.750-2.600 \mathrm{~m}$ & ZEE & Canadá \\
\hline Bacia Lau & Pacifico Sudoeste & $1.700-2.000 \mathrm{~m}$ & ZEE & Tonga \\
\hline Bacia Fiji Norte & Pacífico Sudoeste & $1.900-2.000 \mathrm{~m}$ & ZEE & $F_{i j i}$ \\
\hline Bacia Manus (Leste) & Pacifico Sudoeste & $1.450-1.650 \mathrm{~m}$ & ZEE & $\mathrm{P}$ apua $\mathrm{N}$ ova G uiné \\
\hline $\begin{array}{l}\text { Bacia Mamus } \\
\text { (C entral) }\end{array}$ & Pacifico Sudoeste & $2.450-2.500 \mathrm{~m}$ & ZEE & $\mathrm{P}$ apua $\mathrm{N}$ ova $\mathrm{G}$ uiné \\
\hline Monte Sub. Conical & Pacífico Sudoeste & $1.050-1.650 \mathrm{~m}$ & ZEE & P apua N ova Guiné \\
\hline Calha Okinawa & Pacifico Oeste & $1.250-1.610 \mathrm{~m}$ & ZEE & Japão \\
\hline Rifte de G alápagos & Pacifico Leste & $2.600-2.850 \mathrm{~m}$ & ZEE & Equador \\
\hline CPL $13^{\circ} \mathrm{N}$ & Pacifico Leste & $2.500-2.600 \mathrm{~m}$ & Intemacional & \\
\hline TAG & Atlântico Central & $3.650-3.700 \mathrm{~m}$ & Internacional & \\
\hline
\end{tabular}

Fonte: Herziget al. (2000).

Tabela 3 - Possíveis sítios de mineração de depósitos de sulfetos maciços no fundo do mar.

áreas têm recebido insuficiente atenção dos biólogos, enfatiza-se a necessidade de mais amostragens para melhor conhecimento da natureza de sua fauna.

A conservação das espécies que vivem nos ambientes hidrotermais é essencial para o seu conhecimento científico. As pesquisas sobre essas espécies vêm contribuindo no estudo da origem da vida na Terra, na possibilidade de haver ou ter havido vida em outros planetas, no entendimento da evolução e seleção natural dentro de ecossistemas e em diversos outros tópicos. Ao se elaborarem regras para que se realize a explotação dos minérios em sítios hidrotermais mantendo a preservação das espécies, deve-se levar em consideração características peculiares do sítio, tais como se ele é ativo ou não e qual a distribuição geográfica das espécies que seriam afetadas. Alguns critérios padrões devem ser considerados: i) caracterização do tipo de perturbação; ii) estimativa da perda percentual de habitats de respiradouros do fundo marinho; iii) identificação dos organismos afetados e iv) características da resposta dos organismos à precipitação da pluma hidrotermal.

O desenvolvimento de programas de monitoramento das atividades de mineração em sítios individuais requer informações básicas sobre suas características biológicas, tais como: i) distribuição do habitat dentro da área afetada; ii) composição das espécies e estrutura da comunidade e iii) biologia básica das espécies (meio de alimentação e capacidade de recolonização em um ambiente perturbado).

\section{CONCLUSÃO}

A intensa atividade hidrotermal nos centros de expansão de crosta oceânica produz vida e depósitos minerais de sulfetos metálicos no fundo dos oceanos. Os depósitos não são contínuos globalmente e ocorrem em alguns segmentos de centros de expansão, inclusive aqueles em bacias de retro-arco em limites convergentes de placas. A ocorrência de sítios hidrotermais é proporcional às taxas de expansão oceânica, por esta razão são freqüentemente encontrados na Cadeia do Pacífico Leste. Outros fatores controladores da existência de sítios são também: (1) a interação pontos quentes - cordilheira e (2) a existência de falhamentos. Daí os sítios hidrotermais não serem exclusividade da Cadeia do Pacífico Leste e ocorrerem mesmo no Índico, onde as taxas de expansão são extremamente lentas (menor do que $20 \mathrm{~mm} / \mathrm{ano}$ ).

A maioria dos depósitos até hoje encontrados não são muito amplos e atingem somente centenas de 
milhares de toneladas. Entretanto, esta é uma avaliação baseada em levantamentos sobre a cobertura mais superficial dos depósitos e ainda se conhece muito pouco sobre a extensão dos depósitos em subsuperfície. Considerando a dimensão dos depósitos de sulfetos metálicos no continente, estimase que os depósitos análogos no fundo dos oceanos possam chegar até 100 milhões de toneladas.

A rigor, mais do que $50 \%$ da extensão global das cordilheiras mesoceânicas ainda permanece inexplorada com respeito a atividade hidrotermal e apenas os depósitos mais recentes vêm sendo mapeados. Todavia, os depósitos formados hoje nas cordilheiras mesoceânicas são naturalmente transportados lateralmente pelo processo de expansão oceânico e a atividade hidrotermal ocorre também em litosfera oceânica mais antiga, de até pelo menos 65 milhões de anos de idade.

O conteúdo em metais (ouro e prata inclusive) em alguns depósitos parece atraente para a prospecção, sobretudo em áreas dentro da ZEE de alguns Estados costeiros. O governo da Papua Nova Guiné já licenciou, em 1997, a exploração dos depósitos de sulfetos dentro de suas águas territoriais.

O governo brasileiro ainda não estabeleceu uma política específica para a avaliação dos sulfetos metálicos em oceano profundo, inclusive em torno da região do Arquipélago de São Pedro e São Paulo no Atlântico Equatorial. Como um todo, nossa fronteira a leste permanece inexplorada com respeito aos depósitos em oceano profundo, sejam os sulfetos metálicos, as crostas metalíferas associadas a montes submarinos e platôs marginais ou os nódulos polimetálicos.

O Programa de Geologia e Geofísica Marinha (PGGM) está elaborando projetos de pesquisa específicos para a exploração dos recursos minerais marinhos no âmbito do Programa do Governo Brasileiro para Avaliação dos Recursos Minerais da Plataforma Continental (REMPLAC). Estes projetos devem, em breve, cobrir uma importante lacuna no nosso conhecimento.

\section{AGRADECIMENTOS}

À Sociedade Brasileira de Geofísica (SBGf), ao Departamento de Recursos Minerais do Estado do Rio de Janeiro (DRM/RJ) e à Fundação de Amparo à Pesquisa do
Estado do Rio de Janeiro (FAPERJ) pelo suporte na realização do Seminário Recursos Minerais Marinhos, no LAGEMAR-UFF, em agosto de 2000. Ao Dr. Kaiser de Souza e aos Profs. Peter Rona e Fernando Barriga pela cessão de vasta literatura sobre os depósitos de sulfetos metálicos. A participação no projeto BRIDGE e o trabalho com Prof. Joe Cann nos últimos 4 anos foi fundamental para despertar nosso interesse nos estudo das cordilheiras mesoceânicas e seus depósitos minerais. Sandra Quental é bolsista da Agência Nacional do Petróleo, Programa de Recursos Humanos para o setor Petróleo e Gás - PRH-ANP/MME/ MCT.

\section{REFERÊNCIAS}

ALT, J. C., 1995. Subseafloor processes in midocean ridge hydrothermal systems. In: Humphris, S. E. et al. (Eds), Seafloor Hydrothermal Systems: Physical, Chemical, Biological, and Geological Interactions, American Geophysical Union, Geophysical Monograph N. 91: 85-114.

AMANN, H., 1985. Development of ocean mining in the Red Sea. Marine Mining, 5: 163-172.

AMANN, H., 1989. The Red Sea Pilot Project: lessons for future ocean mining. Marine Mining, 8: 1-22, 1989.

AUZENDE, J. M., PELLETIER, B \&. LAFOY, Y., 1994. Twin active spreading ridges in the North Fiji Basin (southwest Pacific), Geology, 6366.

BAKER， E. T., GERMAN， C. R \& ELDERFIELD, H., 1995. Hydrothermal plumes over spreading-center axes: global distributions and geological inferences, In: Humphris, S. E. et al. (Eds), Seafloor Hydrothermal Systems: Physical, Chemical, Biological, and Geological Interactions, American Geophysical Union, Geophysical Monograph N. 91: 47-71.

BINNS, R. A., SCOTT, S. D., BOGDANOV, Y. A., LISITZIN, A. P., GORDEEV, V. V., GURVICH, E. G., FINLAYSON, E. J., BOYD, T., DOTTER, L. E., WHELLER, G. E. \& MURAVYEV, K. G., 1993. Hydrothermal oxide and gold-rich sulfate deposits of Franklin Seamount, western Woodlark Basin, Papua New Guinea, Econ. Geol., 88: 2122-2153.

BOUGAULT, H., CHALOU, J. L., FOUQUET, Y. \& NEEDHAM, H. D., 1990. Activité hydrothermale et structure axiale des dorsales Est- 
Pacifique et médio-Atlantique, Oceanol. Acta, vol. special 10: 199-207.

BURD, B. J. \& THOMSON, R. E., 1995. Distribution of zooplancton associated with the Endeavour Ridge hydrothermal plume, Journal of Plankton Research, 17: 965-997.

CANN, J. R. \& STRENS, M. R., 1982. Black smokers fuelled by freezing magma, Nature, 298: 147-149.

CRADDOCK, C., HOEH, W. R., GUSTAFSON, W. R., LUTZ, R. G., HASHIMOTO, J. \& VRIJENHOEK, R. C., 1995. Evolutionary relationships among deep-sea mytilids (Bivalvia: Mytilidae) from hydrothermal vents and coldwater methane/sulfide seeps, Marine Biology, 121: 477-485.

CORLISS, J. B., DYMOND, J., GORDON, L. I., EDMOND, J. M., VON HERZEN, R. P., BALLARD， R. D., GREEN， K., WILLIAMS, D., BAINBRIDGE,A., CRANE, K. \& VAN ANDEL, T. H., 1979. Submarine thermal springs on the Galapagos Rift, Science, 203: 1073-1083.

CRUICKSHANK, M. J., 1990. Mining technology for Gorda Ridge sulfides, In: G. R. McMurray (Ed.), Gorda Ridge - a seafloor spreading center in the United States Exclusive Economic Zone, Springer-Verlag, New York, 211-221, 1990.

DEGENS, E. T. \& ROSS, D. A., 1969. Hot Brines and Recent Heavy Metal Deposits in the Red Sea, Springer-Verlag, New York, 600 pp.

DEMETS, C., GORDON, R. G., ARGUS, D. F. \& STEIN, S., 1990. Current plate motions, Geophys. J. Int., 101: 425-478.

FRANCE, S. C., HESSLER, R. R. \& VRIJENHOEK, R. C., 1992. Genetic differentiation between spatially-disjunct populations of the deep-sea hydrothermal vent endemic amphipod Ventiella sulfuris, Marine Biology, 114: 551-556.

FRANCHETEAU, J., NEEDHAM, H. D., CHOUCKROUNE，P., JUTEAU，T., SEGURET, M., BALLARD, R. D., FOX, P. J., NORMAK, W., CARRANZA, A., CORDOBA, D., GUERRERO, F., RANGIN, C., BOUGAULT, H., CAMBON, P. \& HEKINIAN, R., 1979. Massive deep-sea sulfide ore deposits discovered on the East Pacific Rise, Nature, 277: 523-528.

FOUQUET, Y., AUCLAIR, G., CAMBON, P. \& ETOUBLEAU, J., 1988. Geological setting, mineralogical and geochemical investigations on sulfide deposits near $13^{\circ} \mathrm{N}$ on the East Pacific Rise, Marine Geology, 84: 145-178.

FOUQUET, Y., VON STACKELBERG, U., CHARLOU，J. L., DONVAL，J. P., FOUCHER, J. P., ERZINGER, J., HERZIG, P., MÜHE, R., WIEDICKE, M., SOAKAI, S. \& WHITECHURCH, E H., 1991. Hydrothermal activity in the Lau back-arc basin: sulfides and water chemistry, Geology, 19: 303306.

FOUQUET, Y., VON STACKELBERG, U., CHARLOU, J. L., ERZINGER, J. HERZIG, P. M., MÜHE, R. \& WIEDICKE, M., 1993. Metallogenesis in back-arc environments: the Lau Basin example, Econ. Geol., 88: 2154-2181.

GAMO, T., SAKAI, H., ISHIBASHI, J., NAKAYAMA, E., ISSHIKI, K., MATSUURA, H., SHITASHIMA, K., TAKEUCHI, K. \& OHTA, S., 1993. Hydrothermal plumes in the eastern Manus Basin, Bismark Sea: $\mathrm{CH}_{4}, \mathrm{Mn}, \mathrm{Al}$, and $\mathrm{pH}$ anomalies, Deep-Sea Res., 40: 2335-2349.

GERMAN, C. R., BRIEM, J., CHIN, C., DANIELSEN, M., HOLLAND, S., JAMES, R., JÓNSDÓTTIR, A., LUDFORD, E., MOSER, C., OLAFSSON, J., PALMER, M. R. \& RUDNICKI, M. D., 1994. Hydrothermal activity on the Reykjanes Ridge: The Steinahóll Vent-field at $63^{\circ} 06^{\prime} \mathrm{N}$, Earth Planet. Sci. Let., 121: 647-654.

GOLDFARB, M. S., CONVERSE, D. R., HOLLAND, H. D. \& EDMOND, J. M., 1983. The genesis of hot spring deposits on the East Pacific Rise, $21^{\circ} \mathrm{N}$, Economic Geology Monograph 5: 184-197.

HANNINGTON, M. D. \& SCOTT, S. D., 1989. Gold mineralization in volcanogenic massive sulfides: implications of data from active hydrothermal vents on the modern seafloor, Economic Geology Monograph 6: 491-507.

HANNINGTON, M. D., HERZIG, P. M., SCOTT, S. D., THOMPSON, G. \& RONA, 
P. A., 1991. Comparative mineralogy and geochemistry of gold-bearing sulfide deposits on the mid-ocean ridges, Marine Geology, 101: 217 248.

HANNINGTON, M. D., PETERSEN, S., JONASSON, I. R. \& FRANKLIN, J. M., 1994. Hydrothermal activity and associated mineral deposits on the seafloor, Geological Survey of Canada Open File Report, 2915C, Map 1:35,000,000 and CD-ROM.

HANNINGTON, M. D., GALLEY, A. G., HERZIG, P. M. \& PETERSEN, S., 1998. Comparison of the TAG mound and stockwork complex with Cyprus-type massive sulfide deposits, In: Herzig, P. M., S. E. Humphris, J. Miller \& R. A. Zierenberg (Eds), Proceedings of the Ocean Drilling Program, Scientific Results, 158, College Station, TX, 389-415.

HAYMON, R. M. \& KASTNER, M., 1981. Hot spring deposits on the East Pacific Rise at $21^{\circ} \mathrm{N}$ : preliminary description of mineralogy and genesis, Earth Planet. Sci. Let., 53: 363-381.

HAYMON, R. M., FORNARI, D. J., VON DAMM, K. L., LILLEY, M. D., PERFIT, M. R., EDMOND, J. M., SHANKS III, W. C., LUTZ, R. A., GREBMEIER, J. M., CARBOTTE, S., WRIGHT, D., MCLAUGHLIN, E., SMITH, M., BEEDLE, N. \& OLSON, E., 1993. Volcanic eruption of the mid-ocean ridge along the East Pacific Rise crest at $9^{\circ} 45.52^{\prime} \mathrm{N}$ : direct submersible observations of sea floor phenomena associated with eruption event in April, 1991, Earth Planet. Sci. Let., 119: 85-101.

HERZIG, P. M. \& HANNINGTON, M. D., 1995. Polymetallic massive sulfides at the modern seafloor - A review, Ore Geology Review, 10: 95-115.

HERZIG, P. M., FOUQUET, Y., HANNINGTON, M. D. \& VON STACKELBERG, U., 1990. Visible gold in primary polymetallic sulfides from the Lau backarc, AGU Transactions, 71: 1680.

HERZIG, P. M., HANNINGTON, M. D., FOUQUET, Y., VON STACKELBERG, U. \& PETERSEN, S., 1993. Gold-rich polymetallic sulfides from the Lau back-arc and implications for the geochemistry of gold in sea-floor hydrothermal systems of the Southwest Pacific, Econ. Geol., 88: 2182-2209.

HERZIG, P. M., HUMPHRIS, S. E., MILLER, D. J. \& ZIERENBERG, R. A. (Eds.), 1998. Proceedings of the Ocean Drilling Program, Scientific Results, 158, College Station, TX, 427 pp.

HERZIG, P.M., HANNINGTON, M.D. \& PETERSEN, S., 2000. Polymetallic massive sulfide deposis at the modern seafloor and their resource potential, Workshop on Mineral Resources of the International Seabed Area Kingston, Jamaica, 26-30 Junho.

HORIBE, Y. \& CRAIG, H., 1987. Papatua Expedition III: Hydrothermal vents in the Mariana Trough and Kagoshima Bay (Sakurajima Volcano), Eos Trans. AGU, 68: 100.

ISHIBASHI, J.-I., GAMO, T., SAKAI, H., NOJIRI, Y., IGARASHI, G., SHITASHIMA, K. \& TSUBOTA, H., 1988. Geochemical evidence for hydrothermal activity in the Okinawa Trough, Geochem. J., 22: 107114.

JOHNSON, K. S., BEEHLER, C. L. \& SAKAMOTO-ARNOLD, C. M., 1986. A submersible flow analysis system, Anal. Chim. Acta., 179: 245-257.

JUNIPER, K. S., 2000. Impact of the development of polymetallic massive sulphides on the deepsea hydrothermal vent ecosystems, Workshop on Mineral Resources of the International Seabed Area, Kingston, Jamaica, 26-30 Junho.

JUNIPER, S. K. \& TUNNICLIFFE, V., 1997. Crustal accretion and the hot vent ecosystem, Phylosophical Transactions Royal Society of London, A355: 459-474.

JUNIPER, S. K., TUNNICLIFFE, V. \& SOUTHWARD, E. C., 1992. Hydrothermal vents in turbidite sediments on a Northeast Pacific Spreading centre: Organisms and substratum at an ocean drilling site, Canadian Journal of Zoology, 70: 1792-1809.

KADKO,D. \& MOORE, W., 1988. Radiochemical constraints on the crustal residence time of submarine hydrothermal fluids: Endeavour Ridge, Geochimica et Cosmochimica Acta, 52: 659-668. 
KASTNER, M., CRAIG, H., STURZ, A., 1987. Hydrothermal deposition in the Mariana Trough: preliminary mineralogical investigations, AGU Transactions, 68: 1531.

KLINKHAMMER, G., RONA, P., GREAVES, M. \& ELDERFIELD, H., 1985. Hydrothermal manganese plumes in the mid-Atlantic Ridge rift valley, Nature, 314: 727-731.

KLINKHAMMER, G., ELDERFIELD, H., GREAVES, M., RONA, P. \& NELSEN, T., 1986. Manganese geochemistry near hightemperature vents in the Mid-Atlantic Ridge Rift Valley, Earth Planet. Sci. Let., 80: 230-240.

KLINKHAMMER, G. P., CHIN, C. S., RUDNICKI, M., WILSON，C. \& GERMAN, C. R., 1994. Zapping coastal waters for dissolved manganese and blue fluorescence: indicators of runoff, mixing, and exchange, Eos Trans. AGU, 74(44 Supplement): 327.

KRASNOV, S. G., CHERKASHEV, G. A., STEPANOVA, T. V., BATUYEV, B. N., KROTOV, A. G., MALIN, B. V., MASLOV, M. N., MARKOV, V. F., POROSHINA, I. M., SAMOVAROV, M. S., ASHADZE, A.M. \& ERMOLAYEV, I. K., 1995. Detailed geographical studies of hidrothermal fields in the North Atlantic, In: Parson, L. M., C. L. Walker \& D. R. Dixon (Eds), Hydrothermal Vents and Processes, Geological Society Special Publication N. 87: 43-64.

LENOBLE, J-P., 2000. A comparison of possible economic returns from mining deep-sea polymetallic nodules, polymetallic massive sulfides and cobalt-rich ferromanganese crusts, Workshop on Mineral Resources of the International Seabed Area, Kingston, Jamaica, 26-30 Junho.

LITTLE, S. A., STOLZENBACH, K. D. \& VON HERZEN, R. P., 1987. Measurements of plume flow from a hydrothermal vent, J. Geophys. Res., 92: 2587-2596.

MALAHOFF, A., 1982. Massive enriched polymetallic sulfides of the ocean floor - a new commercial source for strategic minerals, Offshore Technology Conference, Houston, TX (USA), 725-730.

MCCOLLOM, T. M. \& SHOCK, E. L., 1997. Geochemical constraints on chemolithoautotrophic metabolism by microorganisms in seafloor hydrothermal systems, Geochimica Cosmochimica Acta, 61: 4375-4391.

MIDDLETON, J. M. \& THOMSON, R. E., 1986. Modeling the rise of hydrothermal plumes, Can. Tech. Rpt. Hydro. and Ocean Sci., 69, Canadian Dept. of Fisheries and Oceans, Sidney, B. C., 18 pp.

MOTTL, M. J., DAVIS, E. \& FISHER, A. T. (Eds), 1991. Proceedings of the Ocean Drilling Program, Scientific Results, 139, College Station, TX.

NAWAB, Z. A., 1984. Red Sea mining: a new era, Deep Sea Research, 31: 813-822.

NELSON, D. C. \& FISHER, C. R., 1995. Chemoautotrophic and methanotrophic endosymbiotic bacteria at deep-sea vents and seeps, In: Karl, D.M. (Ed), The Microbiology of Deep-Sea Hydrothermal Vents, CRC Press, Boca Raton, 125-167.

NISBET, E. G. \& FOWLER C. M. R., 1996. The hydrothermal imprint on life: did heat-shock proteins, metalloproteins and photosynthesis begin around hydrothermal vents?, In: MacLeod, C. J., P. A. Tyler \& C. L. Walker (Eds), Tectonic, Magmatic, Hydrothermal and Biological Segmentation of the Mid-Ocean Ridges, Geological Society Special Publication N. 118: 239-251.

POLLACK, H.N., HURTER，S.J. \& JOHNSTON, J.R., 1990. Heat Loss from the Earth's interior, Reviews in Geophysics, 31: 267280.

RONA, P. A., 1986. Mineral deposits from seafloor hot springs, Scientific American, 254 (1): 84-92.

RONA, P. A., 1988. Hydrothermal mineralization at oceanic ridges, Canadian Mineralogist, 26: 431465.

RONA, P. A. \& SCOTT, S. D., 1993. Preface to Special Issue on the sea-floor hydrotermal mineralization: new perspectives, Econ. Geol., 88: 1935-1976.

RONA, P. A., KLINKHAMMER, G., NELSEN, T. A., TREFRY, J. H., \& ELDERFIELD, H., 1986. Black smokers, massive sulfides and vent biota at the mid-Atlantic Ridge, Nature, 321: 3337. 
SARRAZIN, J. \& JUNIPER, S. K., 1999. Biological characteristics of a hydrothermal edifice mosaic community, Marine Ecology Progress Series, 185: 1-19.

SCOTT, S. D., 1985. Seafloor polymetallic sulfide deposits: modern and ancient, Marine Mining, 5: 191-212.

SPEER, K. G. \& RONA, P. A., 1989. A model of an Atlantic and Pacific hydrothermal plume, J. Geophys. Res., 94: 6213-6220.

STEIN, C. A. \& STEIN S., 1994. Constraints on hydrothermal heat flux through the oceanic lithosphere for global heat flow, Journal of Geophysical Research, 99: 3081-3095.

TAYLOR, B. \& KARNER, G. D., 1983. On the evolution of marginal basins, Rev. Geophys. Space Phys., 21: 1727-1741.

TUNNICLIFFE, V., FOWLER, C. M. R. \& MCARTHUR, A. G., 1996. Plate tectonic history and hot vent biogeography. In: MacLeod, C. J., P. A. Tyler, e C. L. Walker(Eds), Tectonic, Magmatic, Hydrothermal and Biological Segmentation of Mid-Ocean Ridges, Geological Society Special Publication N. 118: 225-238.

TUNNICLIFFE，V., EMBLEY，R.W., HOLDEN, J. F., BUTTERFIELD, D. A., MASSOTH, G. J. \& JUNIPER, S. K., 1997. Biological colonization of new hydrothermal vents following an eruption on Juan de Fuca Ridge, Deep-Sea Res., 44: 1627-1644.

TUNNICLIFFE, V., MCARTHUR, A. G. \& MCHUGH, D., 1998. A biogeographycal perspective of the deep-sea hydrothermal vent fauna, Advances in Marine Biology, 34: 353-441.

TUNNICLIFFE，V., EMBLEY，R.W., HOLDEN, J. F., BUTTERFIELD, D. A., MASSOTH, G. J. \& JUNIPER, S. K., 1997. Biological colonization of new hydrothermal vents following an eruption on Juan de Fuca Ridge, Deep-Sea Research, 44: 1627-1644.

VAN DOVER, C. L., 2000. The ecology of DeepSea Hydrothermal Vents, Princeton University Press, N. J., 424 p.

ZIERENBERG, R. A., FOUQUET, Y. \& MILLER, D. J. - 1996. Leg 169 shipboard scientific party, The roots of seafloor sulfide deposits: preliminary results from ODP Leg 169 drilling in Middle Valley and Escanaba Trough, AGU Transactions, 77: 765.

ZIERENBERG, R. A., FOUQUET, Y., MILLER, D., BAHR J. J. M., BAKER, P. A., BJERKGARD, T., BRUNNER, C. A., DUCKWORTH, R. C., GABLE, R., GIESKES, J., GOODFELLOW, W. D., GRÖSCHEL-BECKER, H. M ., GUERIN, G., ISHIBASHI, J., ITURRINO, G., JAMES, R. H., LACKSCHEWITZ, K. S., MARQUEZ, L. L., NEHLIG, P., PETER, J. M., RIGSBY, C. A., SCHULTHEISS, P., SHANKS III, W. C., SIMONEIT, B. R. T., SUMMIT, M., TEAGLE, D. A. H., URBAT, M. \& ZUFFA, E G. G., 1998. The deep structure of a sea-floor hydrothermal deposit, Nature, 392: 485-488.

\section{NOTE ABOUT THE AUTHORS}

Sidney L. M. Mello

Was born in Brazil on $27^{\text {th }}$ May 1958. He received his B.Sc. in Geology in 1981 and M.Sc. in Marine Geology in 1993 from the Departamento de Geologia of the Universidade Federal do Rio de Janeiro (Brazil). From 1985 to 1986 he was a visiting scholar at the Lamont Doherty Earth Observatory of the Columbia University, USA. In 1999 he obtained his Ph.D. in Marine Geology and Geophysics from the School of Earth Sciences of the University of Leeds, UK. Since
1984 he is a lecturer/researcher at the Laboratório de Geologia Marinha of the Universidade Federal Fluminense (Brazil). His main research interests are tectonic evolution and crustal structure of midocean ridges and continental margins; subsidiary work on hazards to offshore exploration and marine mineral resources. He participated in numerous cruises in ships of the UK, Brazil and other countries, and fieldwork in ocean crust exposed on land in Cyprus. 
Sandra H. A. J. Quental

Was born in Brazil on 25 $5^{\text {th }}$ August 1977. Se received her B.Sc. in Oceanography in 1999 from the Departamento de Oceanografia of the Universidade do Estado do Rio de Janeiro. She is currently working on the structure of the Ascension Fracture Zone (South Atlantic) and finishing her M.Sc. in Marine Geology and Geophysics at the Departamento de Geologia-LAGEMAR of the Universidade Federal
Fluminense (Brazil). Her main research interests are tectonic evolution and crustal structure of fracture zones and continental margins; subsidiary work on gravity modeling and marine mineral resources. She participated in two scientific cruises, including a Meteor Cruise (M49-3/2001) on the Argentine and Brazilian Basins. Sandra Quental is a fellow of the Agência Nacional do Petróleo (ANP).

\section{UENF - North Fluminense State University}

\section{LENEP - (Petroleum Exploration and Engineering Laboratory)}

Offers an undergraduate course in Petroleum \& Engineering and a graduate course leading to Master's and PhD's degrees in Reservoir and Exploration Engineering. LENEP has a multidisciplinary staff of $13 \mathrm{PhD}$ and $5 \mathrm{MSc}$ distributed over sections of Applied Geophysics, Geology and Geochemistry, Petroleum Engineering, Petrophysics and Computing.

Visit http://www.uenf.br

\section{INPE/MCT - National Institute for Space Research}

\section{Graduate Program in Space Geophysics}

It offers graduate courses in Space Geophysics leading to Master's and PhD's degrees offered by a staff of 36 academic PhD. The main areas of interest are: Upper Atmosphere Physics, Airglow, Low and Middle Atmosphere, Atmospheric Electricity, Geomagnetism, Ionosphere and Magnetosphere-Heliosphere.

www.inpe.br/PosGraduaçao/Geofisica_Espacial/Pagina_inicial_GES.htm 